\title{
Sistema pesqueiro da Baía da Babitonga, litoral norte de Santa Catarina: uma abordagem etnoecológica
}

\section{The fishing system of Babitonga Bay on the north coast of Santa Catarina, Brazil: an ethnoecological approach}

\author{
Luciana PINHEIRO* \\ Marta CREMER $^{* *}$
}

\section{RESUMO}

Este artigo caracteriza o sistema de pesca artesanal na Baía da Babitonga, região estuarina do litoral norte de Santa Catarina. Descreve as modalidades de pesca, formas de exploração dos recursos, características dos petrechos e dinâmicas na transformação da pesca local. A pesquisa se apoiou em entrevistas parcialmente estruturadas, com informantes especialistas, e entrevistas semi-estruturadas, com informantes aleatórios.

Palavras-chave: etnoecologia, pesca artesanal, Baía da Babitonga.

\begin{abstract}
This paper describes artisanal fisheries in Babitonga Bay, northern coast of Santa Catarina State, Brazil. Types of fisheries, practices of resource exploration, characteristics of gear and transformations in the fisheries system are described. This research was strongly based on the local ecological knowledge of fishermen, obtaining data from interviews with local experts, as well as questionnaires applied to randomly selected fishermen.

Key words: ethnoecology, artisanal fisheries, Babitonga Bay.
\end{abstract}

* Bióloga. Doutoranda em Meio Ambiente e Desenvolvimento pela Universidade Federal do Paraná. <lucianapbio@hotmail.com>

** Bióloga. Doutoranda em Zoologia pela Universidade Federal do Paraná.<mcremer@ilhanet.com.br> 
Cet article présente les caractéristiques du système de pêche artisanale employé à la baie de Babitonga, côte du nord de Santa Catarina, au Brésil. Il décrit les modalités de pêche, les formes d'exploitation de la ressource, les caractéristiques des outillages et les dynamiques dans la transformation de la pêche locale. Des entrevues avec des informateurs spécialistes et aléatoires ont guidé cette recherche, qui s'est basée sur la connaissance des pêcheurs.

Mots clefs: Ethnoécologie, pêche artisanale, Baie de Babitonga.

\section{Introdução}

A pesca artesanal é realizada em toda a extensão costeira do estado de Santa Catarina, principalmente nas baías, lagoas e estuários, beneficiando direta ou indiretamente 150 mil pessoas. Na Baía da Babitonga, localizada no litoral norte do estado, existem 33 comunidades ligadas a essa atividade que agregam 1.089 pescadores (RODRIGUES et al., 1998).

De acordo com o artigo $2 .^{\circ}$ da Lei $n .^{\circ} 10.164$, de 11 de maio de 1994, a pesca artesanal é definida como "pesca profissional exercida ou não com embarcação pesqueira, desde que sem vínculo empregatício com indústria, praticada em águas litorâneas e interiores com fins complementares ao regime de economia familiar". Rios (1976) tipifica a pesca artesanal a partir de uma série de características: embarcações e equipamentos rústicos ou de baixo custo; produção não organizada em grande escala; ausência de um sistema de frotas, com as embarcações pertencentes, em geral, a um único proprietário; inexistência de vínculo empregatício; parte da produção destinada ao auto-sustento; remuneração do tripulante com produto in natura, pelo sistema de meação.

As características da pesca artesanal, que tem suas práticas baseadas no conhecimento tradicional, transmitido de geração para geração, tornam essa atividade particularmente apropriada para abordagens etnoecológicas. A etnoecologia é a ciência que investiga como a natureza é vista, manejada e apropriada pelos grupos humanos (TOLEDO, 1992). Segundo Marques (2001), a etnoecologia leva em conta o ethnos ("povo", "cultura") na oikos ("casa", "ambiente"), agindo de forma interdisciplinar, ao fazer a ligação entre as ciências sociais e naturais. Nesse sentido, pode ser entendida como uma ciência em ascensão, que dialoga com a biolo- gia e com a antropologia, integrando aspectos intelectuais e práticos em sua abordagem (TOLEDO, 1992).

Nesse contexto, a recuperação do conhecimento tradicionail e sua inserção no corpo de conhecimento científico é uma das bases essenciais para diversas áreas de pesquisa e para futuras propostas de conservação das espécies. Além de possibilitar o acesso da própria comunidade a informações sistematizadas.

A abordagem interdisciplinar da pesca artesanal é recente na história da pesquisa pesqueira e sua necessidade se coloca definitivamente apenas a partir do final dos anos 80 (DURAND; LEMOALLE; WEBER, 1991). Quensière (1996) considera que as abordagens setoriais para a compreensão e gestão da pesca foram um fracasso, enquanto Charles (1991) aponta que a pesquisa pesqueira deve se voltar para a busca de modelos integrados dos sistemas de pesca artesanal, que incluam as dinâmicas complexas das sociedades de pescadores, assim como o comportamento dos estoques e das frotas. Mesmo assim, as abordagens interdisciplinares são ainda raras e o setor pode ser considerado relativamente desconhecido sob esse prisma. Uma das recomendações finais do Simpósio da Fundação Universidade de Rio Grande (FURG) sobre Pesquisa Pesqueira, que contou apenas com a participação de pesquisadores das ciências naturais, é a de "atualizar a caracterização da pesca artesanal, visando definir sua real estruturação tecnológica, social e econômica nas diferentes regiões do país" (CASTELlo; HAIMOVICI, 1991).

Uma ferramenta teórica que tem permitido a abordagem interdisciplinar da pesca artesanal é a sua concepção de sistema de produção como novo nível de integração entre os ecossistemas aquáticos e a sociedade de pescadores. Adaptando a definição aplicada a sistemas agrícolas por autores franceses, Andriguetto Filho (2002) define sistema de produção pesqueiro como 
"o modo de combinação entre um meio aquático definido, força e meios de trabalho, com a finalidade da captura de recursos vivos aquáticos, comum a um conjunto de unidades de produção". Quensière (1994) utiliza a expressão "sistemas de produção" sem defini-la, mas sua análise das pescarias tradicionais do Delta do Niger usa uma concepção ainda mais ampla, que inclui, entre outros elementos, a organização social dos grupos de pescadores, especialmente as relações que determinam a gestão do recurso e o acesso ao mesmo, suas migrações e estratégias de comercialização. A aplicação do conceito de sistema de produção à pesca foi feita também pelos geógrafos. Para Corlay (1995), um "sistema haliêutico" e seu "espaço haliêutico" - a estrutura espacial que o próprio sistema gera - constituem um "geosistema haliêutico". O geo-sistema haliêutico resulta do encontro do potencial dos recursos aquáticos (o ecossistema) e de uma estratégia de valorização desse potencial (o sociossistema). O conjunto dos componentes naturais e sociais, em interação, constitui o sistema haliêutico. Em um estudo extenso e detalhado da pesca e do uso dos recursos aquáticos na Casamance, no Senegal, outra geógrafa, Cormier-Salem (1992), analisa, em seu contexto de trabalho,

...as relações de interdependência entre os diversos componentes da pesca, a saber, o meio aquático (físico), os recursos tróficos, as técnicas de pesca, as comunidades de pescadores e a organização social e econômica da pesca.

Essa concepção interdisciplinar e sistêmica da pesca artesanal inspirou este trabalho, que tem por objetivo descrever a pesca artesanal desenvolvida no estuário da Baía da Babitonga, fornecendo informações etnográficas sobre as modalidades de pesca, as formas de exploração dos recursos, as características dos petrechos e as dinâmicas na transformação da pesca local por meio de uma abordagem etnoecológica. Pretende fornecer os primeiros subsídios para a futura implementação de modelos adequados de manejo, normatização dos períodos de pesca, espécies e petrechos e adoção de estratégias conservacionistas mais coerentes.

\section{Área de estudo e análise dos dados: procedimentos metodológicos empregados}

A Baía da Babitonga, localizada na região norte do Estado de Santa Catarina, entre $26^{\circ} 02^{\prime}-26^{\circ} 28^{\prime}$ S e $48^{\circ} 28^{\prime}$ $-48^{\circ} 50^{\prime} \mathrm{W}$, constitui um importante ecossistema estuarino na Região Sul do Brasil. É contornada na porção noroeste pela Serra do Mar e a sudeste pela Ilha de São Francisco do Sul (SILVA, 1995). Seus manguezais abrangem aproximadamente $6.200 \mathrm{ha}$, propiciando significativo desenvolvimento de aves, peixes, moluscos, crustáceos e cetáceos, entre outros (FATMA, 1984; RODRIGUES et al., 1998).

$O$ estudo foi feito no período de março a dezembro de 2002, com pescadores residentes nas comunidades pesqueiras de Frias, Vila da Glória, Praia Bonita, Praia de Paulas, Praia do Mota e Ilha do Mel, todas elas localizadas na Baía da Babitonga (São Francisco do Sul).

A coleta e análise dos dados etnoecológicos seguiu o método proposto por Marques (2001). Foram sujeitos iniciais da pesquisa seis pescadores que detêm vasto conhecimento da região, assim reconhecidos pela população e que assim se auto-identificam. As informações desses informantes especialistas foram fornecidas por meio de entrevistas parcialmente estruturadas.

A coleta dos dados referentes às características das redes foi feita por meio de entrevistas semiestruturadas com 29 pescadores, tratados como informantes aleatórios.

\section{A pesca local: tradicionalidade e modelo artesanal}

\section{$O$ contexto natural e social}

A pesca artesanal é a principal atividade realizada pela população local, para fins de subsistência ou comerciais. Além da pesca e exploração dos recursos da mata atlântica, como a caça, extração de palmito, outros vegetais e madeira, pratica-se ainda a agricultura, agora em menor escala. Existem também, na região da Vila da Glória, cerca de dez engenhos de farinha ativos. 
O modelo de pesca pode ser caracterizado como oportunista, uma vez que as saídas dos pescadores para o mar sempre dependem das condições do tempo e de maré. A pescaria é regida por um calendário que coincide com a abundância de determinadas espécies de peixes (quadro 1). O mercado também é importante. Na "safra" do camarão, por exemplo, o valor deste é menor; já na entressafra, seu preço sobe, mas os pescadores se dedicam à pesca de outros recursos e/ou à confecção de redes. Essa estratégia é diferente para os camaroeiros, que vão pescar em alto-mar ou, ajudados pelo aumento do preço, continuam pescando na baía, mas com pouco resultado.

\section{Exploração dos recursos pesqueiros: técnicas $e$ estratégias}

A pesca artesanal local é baseada principalmente na utilização de tarrafas, gerivais, redes de emalhe e redes de arrasto (RODRIGUES et al., 1998). Os diferentes petrechos de pesca são voltados para determinadas espécies-alvo (tabela 1 ).

O gerival, gerivá ou berimbau é um aparelho que apreende camarão, seletivamente, como uma rede de arrastão de fundo. Funciona com a força da maré, embora os pescadores venham praticando essa modalidade de pesca com o motor ligado e em movimento lento, maximizando a pesca e extraindo o camarão de maneira predatória.
Na pesca de caceio, a rede anda solta, ao sabor da maré, indo de encontro ao peixe, que corre contra a maré. Por essa razão, a pesca de caceio é utilizada na lua de quarto, ou maré de quarto (maré da lua crescente e minguante). A rede vai até o fundo e duas bóias a mantêm em posição vertical na coluna d'água. A embarcação acompanha a rede.

A pesca de palanqueio ou fundeio tem a rede fixa ao fundo por poitas (pedras ou outro peso), marcada com duas bóias. A rede, chamada, pois, de rede de espera, fica assim instalada por algum tempo, geralmente durante toda a noite. Muitos pescadores deixam-na afixada no local de pesca durante todo o quarto de lua, fazendo duas revistas ao dia, para recolher o peixe nela emalhado. Entretanto, alguns julgam essa prática predatória, uma vez que amplia a captura dos peixes.

$\mathrm{Na}$ pesca de cerco, a rede é estaqueada próxima das formações de gramíneas (Spartina sp), na região entremarés. Peixes adultos não costumam saltar por cima da rede, mas muitos juvenis ficam presos e são posteriormente desprezados.

A pesca de rodeio ou redondo é realizada pela disposição da rede em círculo e, com a embarcação no centro, o pescador bate na água com o remo ou com uma poita amarrada em uma corda, assustando o peixe, que corre e se emaranha na rede.

Para a pesca de lanço, lance ou arrasto de praia puxa-se a rede até a areia da praia.

O espinhel, utilizado principalmente para a captura de badejões, consiste numa corda com anzóis e iscas,

QUADRO 1 - ETNOCALENDÁRIO DA PESCA NA BAÍA DA BABITONGA, DE ACORDO COM INFORMAÇÕES ETNOGRÁFICAS

\begin{tabular}{|c|c|c|c|c|c|c|c|c|c|c|c|c|c|c|}
\hline Etnoespécie & Arte de pesca & $\begin{array}{c}\text { Característica } \\
\text { petrecho }\end{array}$ & $\mathbf{J}$ & $\mathbf{F}$ & $\mathbf{M}$ & $\mathbf{A}$ & $\mathbf{M}$ & $\mathbf{J}$ & $\mathbf{J}$ & $\mathbf{A}$ & $\mathrm{S}$ & $\mathbf{O}$ & $\mathbf{N}$ & D \\
\hline Badejão & Espinhel & anzol $20 ; 30$ & $\sqrt{2}$ & $\sqrt{20}$ & 2 & 2 & 2 & 212. & प्र & 212 & 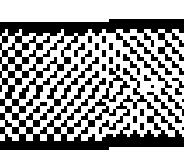 & 2 & 12 & \\
\hline Betara & Cerco/tarrafa & \#5 a 8 & & & & & & 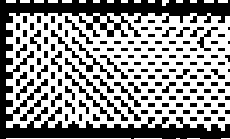 & 2 & & & & & \\
\hline Corvina & Fundeio & $\# 12$ a 14 & & & & & & & & & (2) & 12 & 27 & \\
\hline Gaivira & Palanqueada e boiada & $\# 12$ a 14 & & & & & & & & & & & 표 & 2. \\
\hline Linguado & Palanqueio & $\# 18$ a 27 & & & & & 20 & II) & 2. & 2 & & & & \\
\hline Miraguaia & Palanqueio/caceio & $\# 22$ a 27 & & & & & & & & T: & 2 & 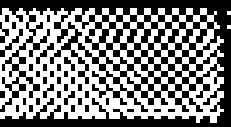 & 2 & \\
\hline Parati crioulo & Redondo/caceio/cerco/tarrafa & $\# 5,6,7$ & 218 & 1.7. & 12 & 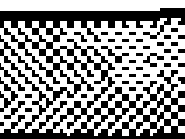 & 12.2. & 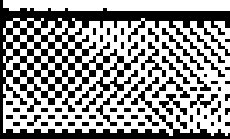 & 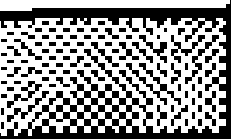 & 2 & 20 & 1. & $\sqrt{1.8}$ & 2 \\
\hline Parati sabão & Redondo/caceio/cerco/tarrafa & $\# 5,6,7$ & & & & & & & r & & & $\overline{2}$ & 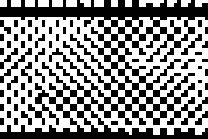 & I. \\
\hline Parati apoá & Redondo/caceio/cerco/tarrafa & $\# 5,6,7$ & $1=2$ & & & & & & & & & & 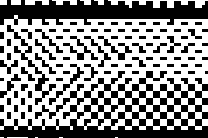 & 2 \\
\hline Parati grosso & Redondo/caceio/cerco/tarrafa & $\# 5,6,7$ & & & & & & 2 & 2 & & & & & \\
\hline Pescada-amar. & Palanqueio/caceio & $\# 17$ a 23 & & & & & & & & & & 20 & $2=2$ & 2.2 \\
\hline Pescadinha br. & Caceio & $\# 5$ a 7 & & & $2=2$ & 20 & & 2 & 2 & 2 & & & & \\
\hline Tainha & Redondo/caceio/cerco/tarrafa & $\# 6$ a 12 & & & & & 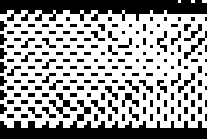 & 212 & $=$ & 2.1. & & & & \\
\hline Tainha crioula & Redondo/caceio/cerco/tarrafa & $\# 6$ a 12 & 2 & 20 & & 12 & 2 & ? & $=$ & 2 & & & 2 & \\
\hline Tainhota & Redondo/caceio/cerco/tarrafa & $\# 6$ a 12 & $\overline{2}$ & 2 & & 12 & 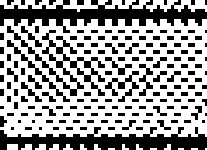 & प्य & 21 & 2 & & 28 & 2.) & 2 \\
\hline Diversas & Rede feiticeira & NI & 2 & 1.: & 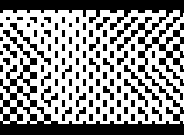 & & $2=$ & 2 & & 2 & & & & 2.2 \\
\hline
\end{tabular}


PINHEIRO, L.; CREMER, M. Sistema pesqueiro da Baía da Babitonga, litoral...

TABELA 1 - FORMAS DE EXPLORAÇÃO DOS RECURSOS PESQUEIROS

\begin{tabular}{l|l}
\hline Arte de pesca & Etnoespécies-alvo \\
\hline Gerival & Camarão \\
\hline Arrasto de praia & Tainha, tainhota, bagre, betara, saguá, culapada, parati, robalinho \\
\hline Caceio & Tainha, tainhota, parati, robalo, pescadinha, betara, curuca, pescada-amarela, linguado, parati, camarão \\
\hline Palanqueio & Linguado, pejereva, pescada-amarela, miraguaia, tainha, bicuda, coroca, badejo \\
\hline Cerco & Tainha, tainhota, parati \\
\hline Espinhel & Badejão \\
\hline Redondo & Parati, tainha, tainhota \\
\hline
\end{tabular}

geralmente bagres. Os peixes são fisgados quando se dirigem com rapidez sobre a presa (isca).

A pesca de arrastão é feita a motor. De ocorrência ocasional, sua prática é proibida na baía.

A tabela 2 apresenta, dispostos em ordem alfabética, os peixes de maior representatividade comercial, de acordo com a informação dos entrevistados. A nomenclatura científica adotada foi baseada nos estudos de Rodrigues et al. (1998), realizados na Baía da Babitonga.

A produção pesqueira geralmente é beneficiada pela família do pescador, em particular pela mulher. Atualmente, a comercialização é efetuada pela venda a restaurantes, turistas, demais habitantes da região, peixarias e indústrias de pesca (beneficiadoras), embora a economia local já tenha sido baseada na troca.

$\mathrm{Na}$ tabela 3, são descritas algumas estratégias de pesca utilizadas para a captura dos peixes de maior importância comercial na Baía da Babitonga.

É possível afirmar que o conhecimento acerca da ecologia dos peixes é essencial para o desenvolvimento das técnicas de captura. De acordo com Gadgil et al. (1993), apud Begossi et al. (2002), essa sabedoria certamente está relacionada ao sedentarismo dessas comunidades, o que lhes possibilita um maior contato com o ecossistema e, portanto, percepção e conhecimentos mais aprofundados sobre seu funcionamento.

\section{Características dos instrumentos de pesca}

Nas entrevistas semi-estruturadas e parcialmente estruturadas com pescadores da Babitonga, foram coletados dados sobre 76 tipos de rede de emalhe utilizados na pesca artesanal local. Obtiveram-se as dimensões das redes, as etnoespécies-alvo e o tempo de uso na água, entre outras informações (tabela 4).
O uso de cada tipo de rede está relacionado com a abundância de determinadas espécies de peixe, sua época de pesca e a estratégia empregada, possibilitando a formulação de um etnocalendário da pesca local, já apresentado no quadro 1.

As embarcações utilizadas pela pesca artesanal no interior da baía são bateiras, barcos de madeira e alumínio, voadeiras e canoas a remo, motor ou vela. Os motores, de popa e centro, a diesel e a gasolina, têm entre $4 \mathrm{e}$ $45 \mathrm{HP}$.

Nota-se que os dados obtidos via informantes aleatórios nem sempre coincidem com aqueles declarados pelos informantes especialistas (tabela 4), o que parece acentuar o valor do conhecimento dos informantes especialistas. Também se percebe uma variabilidade nas informações, principalmente quanto ao calendário de pesca, que, de acordo com os pescadores, depende da distribuição geográfica e sazonal dos peixes dentro da baía.

Dinâmica na exploração dos recursos pesqueiros: perspectiva histórica e dimensão socioambiental

De acordo com os informantes, a pesca local sofreu muitas transformações ao longo do tempo. Tais transformações dizem respeito ao destino e consumo do pescado e técnicas empregadas na pesca.

Antigamente, não havia geladeira ou freezer. ${ }^{1}$ As mulheres defumavam o pescado, o que possibilitava o estoque temporário. Caso o peixe e o camarão não fossem consumidos no prazo do estoque, eram descartados.

A pesca era para o consumo diário e não para o acúmulo. Os peixes eram escolhidos na praia. Seleciona-

1 Antes da introdução da geladeira e do frezer, costumava-se conservar o pescado para defumação. Os recursos eram abundantes e o que sobrava era distribuído aos demais moradores da comunidade ou abandonados na praia e consumidos pelas aves marinhas. Hoje, a maioria dos pescadores possui freezer e estocam o quanto podem. A "cultura do freezer" certamente estimulou a exploração intensa dos recursos naturais. 
PINHEIRO, L.; CREMER, M. Sistema pesqueiro da Baía da Babitonga, litoral...

TABELA 2 - PRINCIPAIS ESPÉCIES DE PEIXES DE INTERESSE COMERCIAL DA BAÍA DA BABITONGA E SEU CORRESPONDENTE TAXONÔMICO

\begin{tabular}{l|l}
\hline \multicolumn{1}{c|}{ "Antigamente" } & \multicolumn{1}{c}{ "Hoje em dia" } \\
\hline $\begin{array}{l}\text { Até 1950, 1960: barbantão } \\
\text { De 1960 até 1970: fio de seda }\end{array}$ & Desde 1970: fio de nylon plástico \\
\hline 1960,1965: a pesca ocorria apenas na costa (praia, próximo da areia ) & Desde 1965: pesca no canal (quase ninguém pesca na costa) \\
\hline Pesca de engodo & Uso do gerival \\
\hline Mulheres faziam redes & Maioria dos "panos de rede" são comprados \\
\hline Cortiça de pau & \\
\hline Arrasto de gerival com força da maré & Uso de motor de popa no gerival \\
\hline
\end{tabular}

\section{TABELA 3 - ESTRATÉGIAS DE PESCA ADOTADAS PELOS PESCADORES DA BAÍA DA BABITONGA.}

\begin{tabular}{|c|c|c|}
\hline Etnoespécie & Técnicas de captura & $\begin{array}{l}\text { Conhecimento do nicho/comportamento associado à captura das } \\
\text { etnoespécies }\end{array}$ \\
\hline Badejão & $\begin{array}{l}\text { "O badejão pega ele de espinhel. Pega muito também é de } \\
\text { mergulho. No arpão, de mergulho." }\end{array}$ & "É difícil. Ele fica na toca de pedra. O pessoal de mergulho vê ele." \\
\hline Corvina & $\begin{array}{l}\text { "A corvina pega de rede, pega de espinhel, pega de linha. } \\
\text { Pega no anzol" }\end{array}$ & $\begin{array}{l}\text { "Esse é um peixe de profundidade. Só se sabe onde ela está quando... } \\
\text { Agora no verão é época que ela fala. Quando tá pra trovoar, quente, } \\
\text { ela fala muita coisa. Quanto mais quente o dia, mais ela fala." }\end{array}$ \\
\hline Linguado & $\begin{array}{l}\text { "Pega mais na rede. Pega na rede. Matavam muito na fisga. } \\
\text { Agora tá proibido matar [na fisgal." }\end{array}$ & "Peixe de profundidade também." \\
\hline Miraguaia & $\begin{array}{l}\text { "Rede. Pega no anzol também. Rede de malha clara. Malha } \\
\text { clara é malha grande que a gente chama." }\end{array}$ & $\begin{array}{l}\text { "Pra saber onde ela está, só ouvindo ela falá também. É um peixe que } \\
\text { anda encardumado. E quando uma mete a cara na rede e canta, que } \\
\text { quer dizer, fala continuado..." }\end{array}$ \\
\hline Parati & $\begin{array}{l}\text { "Se pega na rede de malha miúda e tarrafa. [...] só arrodeia e } \\
\text { bate pra ele corrê e malhá na rede." }\end{array}$ & $\begin{array}{l}\text { "Isso é o movimento da água. As água vem tremendo um tremido } \\
\text { diferente." }\end{array}$ \\
\hline Pescada-amarela & $\begin{array}{l}\text { "Ela também se pega na linha, no anzol, e também se mata } \\
\text { na rede. Antigamente matava-se muito no espinhel. Agora é } \\
\text { na rede. Na rede fundiada. E caceio também. Matam mais } \\
\text { fundiada." }\end{array}$ & $\begin{array}{l}\text { "Peixe de profundidade também. Se vai passando uma embarcação a } \\
\text { remo ou pára, daí escuta ela falando. Parece que tão batendo numa } \\
\text { lata velha. Pau, pau, pau." }\end{array}$ \\
\hline Tainha & $\begin{array}{l}\text { "Rede e tarrafa" } \\
\text { "Mata até no seco." }\end{array}$ & $\begin{array}{l}\text { "Refolhando na água, que nem tainhota." } \\
\text { "Fica grosso a água." }\end{array}$ \\
\hline Tainhota & "Rede e tarrafa." & "Mexe na água, pula, ressolha." \\
\hline
\end{tabular}

dos, iam para a casa. Os que não eram selecionados eram deixados na areia. Hoje, devido à escassez, todos os peixes são utilizados. ${ }^{2}$ Essa situação da Baía da Babitonga certamente reflete uma progressiva diminuição na disponibilidade de recursos. Ainda com relação ao descarte de peixes na praia, um pescador, que não é um dos informantes especialistas, comentou que esses restos servem de alimento para os outros peixes, que habitam o fundo, e que isso está recomendado na Bíblia.
Ainda se pratica a doação de pescado, embora não tão significativamente como antes, em especial entre parentes e amigos.

Com o correr do tempo, mudanças na tecnologia da pesca também foram significativas, seja no aspecto de forrageio ótimo, seja no que se refere à (sobre)exploração do recurso. A tabela 5 ilustra algumas dessas mudanças.

Segundo Ricklefs (1996), a pesca, assim como a caça, o desmatamento e outras formas de extração de produtos

2 É interessante notar que, em algumas comunidades (Laguna, no sul do Estado, por exemplo) ainda ocorre essa tradição de escolher o peixe na areia, selecionando somente aqueles maiores e mais procurados. Os peixes não selecionados são ali mesmo abandonados, morrendo na beira da praia e sendo consumidos por aves. Ouvese também que esses peixes abandonados na areia são o quinhão do pescador para as gaivotas.

3 Baseado em Rodrigues et al. (1998)

4 Baseado em Rodrigues et al. (1998) e ictiólogos interlocutores.

5 Paralichthys e outros gêneros de Paralichthyidae estavam anteriormente incluídos na família Bathidae. 
da natureza, constituem clássicas formas de interação consumidor-recurso. Normalmente, tais relações atingem estados estacionários: os recursos escasseiam e a eficiência na exploração decai. Em conseqüência, a população de consumidores passa a declinar ou procura recursos alternativos, até que consumidor e recurso alcancem novamente o equilíbrio. Entretanto, a habilidade humana na exploração dos ecossistemas tomou proporções tais que os recursos renováveis podem se esgotar num futuro muito próximo.
Além da evolução na tecnologia empregada na pesca (tabela 3) e das acuradas estratégias de pesca (tabela 3), o aumento do número de embarcações e de pescadores competindo pelo mesmo recurso parece ser o principal determinante da redução dos estoques pesqueiros. Tal redução implica uma crescente disputa social entre pescadores profissionais e amadores, conflitos de valores éticos e busca de outros meios de sobrevivência familiar. Os conflitos ligados à pesca na Babitonga são referentes ao crescente número de pescadores, em sua maioria não

TABELA 4 - CARACTERÍSTICAS DAS REDES DE EMALHE MAIS EMPREGADAS NA BAÍA DA BABITONGA PELA PESCA ARTESANAL, DE ACORDO COM INFORMAÇÕES DOS PESCADORES ARTESANAIS

\begin{tabular}{|c|c|c|c|c|c|c|c|c|c|c|}
\hline E-sp. & MP & $\#$ & $L$ & $\mathrm{H}$ & $\varnothing$ & $\mathbf{T}$ & $f$ & LC & $\mathbf{P r}$ & $t$ \\
\hline Linguado & $\begin{array}{l}\text { palanque } \\
\text { caceio }\end{array}$ & 20 a 26 & $\begin{array}{l}100 \mathrm{a} \\
500\end{array}$ & 2 a 3,5 & $\begin{array}{l}0,40 \mathrm{a} \\
120\end{array}$ & abr. a set. & $4^{\circ}$ de lua & $\begin{array}{l}\text { laje, lama, } \\
\text { baixio, }\end{array}$ & $\begin{array}{l}2 \text { a } 15 \\
m\end{array}$ & $\begin{array}{l}\text { palanque: } 12 \\
\text { h ou semana; } \\
\text { caceio: } 3 \mathrm{~h}\end{array}$ \\
\hline Tainha & $\begin{array}{l}\text { caceio } \\
\text { redondo } \\
\text { palanque } \\
\text { cerco }\end{array}$ & 10 a 12 & $\begin{array}{l}100 \mathrm{a} \\
700\end{array}$ & 2 a 11 & $\begin{array}{l}0,30 a \\
0,60\end{array}$ & $\begin{array}{l}\text { ano inteiro, } \\
\text { principalmen } \\
\text { te maio e } \\
\text { agosto }\end{array}$ & $\begin{array}{l}\text { quase todos } \\
\text { os dias }\end{array}$ & $\begin{array}{l}\text { Baixio, } \\
\text { laje, } \\
\text { costa, } \\
\text { coroa, } \\
\text { canal } \\
\text { limpo }\end{array}$ & $\begin{array}{l}, 5 \text { a } 12 \\
m\end{array}$ & $\begin{array}{l}\text { rodeio: } 1 \mathrm{~h} ; \\
\text { palanque: } 12 \\
\mathrm{~h} \text { a } 3 \text { ou } 4 \\
\text { dias; caceio: } \\
40 \text { min, em } 6 \\
\mathrm{~h}\end{array}$ \\
\hline Tainhota & $\begin{array}{l}\text { caceio } \\
\text { palanquei } \\
\text { o } \\
\text { cerco } \\
\text { arrasto }\end{array}$ & 5 a 10 & $\begin{array}{l}120 a \\
780\end{array}$ & 2,5 a 5 & $\begin{array}{l}0,30 \mathrm{a} \\
0,40\end{array}$ & ano inteiro & $\begin{array}{l}5 \\
\text { dias/semana } \\
\text {; todos os } \\
\text { dias }\end{array}$ & $\begin{array}{l}\text { costão, } \\
\text { capim, } \\
\text { coroas }\end{array}$ & $\begin{array}{l}\text { raso a } \\
15 \mathrm{~m}\end{array}$ & $\begin{array}{l}\text { caceio/arrasto } \\
: 4 \mathrm{~h} \text {; fundeio: } \\
12 \mathrm{~h} \text {; cerco: } 5 \\
\text { a } 6 \mathrm{~h}\end{array}$ \\
\hline Pescada & $\begin{array}{l}\text { palanque } \\
\text { caceio }\end{array}$ & 18 a 22 & $\begin{array}{l}100 \mathrm{a} \\
600\end{array}$ & 1,8 a 7 & $\begin{array}{l}100 \mathrm{a} \\
140\end{array}$ & $\begin{array}{l}\text { jun a mar; } \\
\text { principalmen } \\
\text { te out a dez }\end{array}$ & $\begin{array}{l}12 \text { a } 15 \\
\text { dias/mês }\end{array}$ & $\begin{array}{l}\text { laje, } \\
\text { canal, } \\
\text { cascalho }\end{array}$ & $\begin{array}{l}8 \text { a } 18 \\
m\end{array}$ & $\begin{array}{l}\text { palanque: } 12 \\
\text { h a } 15 \text { dias; } \\
\text { caceio: } 3 \text { a } 6 \mathrm{~h}\end{array}$ \\
\hline Camarão & $\begin{array}{l}\text { caceio } \\
\text { arrasto }\end{array}$ & $5(6)$ & $\begin{array}{l}100 a \\
400\end{array}$ & $\begin{array}{l}1,5 \mathrm{a} \\
2,5\end{array}$ & $\begin{array}{l}0,25 \mathrm{e} \\
0,30\end{array}$ & $\begin{array}{l}\text { ano inteiro; } \\
\text { fev. a abr; } \\
\text { fev. a jun. }\end{array}$ & $\begin{array}{l}12 \text { a } 20 \\
\text { dias/mês }\end{array}$ & $\begin{array}{l}\text { lodo, } \\
\text { costão, } \\
\text { lugar } \\
\text { limpo, } \\
\text { baixio, } \\
\text { canal. }\end{array}$ & $\begin{array}{l}\text { raso a } \\
10 \mathrm{~m}\end{array}$ & $4 \mathrm{a} 12 \mathrm{~h}$ \\
\hline Miraguaia & $\begin{array}{l}\text { palanque } \\
\text { caceio }\end{array}$ & 22 a 28 & $\begin{array}{l}140 \mathrm{a} \\
600\end{array}$ & 1,8 a 7 & $\begin{array}{l}0,70 \mathrm{a} \\
120\end{array}$ & $\begin{array}{l}\text { maio a dez., } \\
\text { principalmen } \\
\text { te out a dez. }\end{array}$ & $\begin{array}{l}\text { maré de } 4^{\circ} \\
\text { (7 dias) }\end{array}$ & $\begin{array}{l}\text { canal, } \\
\text { laje, lama } \\
\text { pedra }\end{array}$ & $\begin{array}{l}6 \text { a } 18 \\
m\end{array}$ & $\begin{array}{l}\text { palanque: } 6 \mathrm{~h} \\
\text { a } 5 \text { dias; } \\
\text { caceio: } 2 \text { a } 6 \mathrm{~h}\end{array}$ \\
\hline Parati & $\begin{array}{l}\text { caceio } \\
\text { cerco } \\
\text { redondo }\end{array}$ & 6 a 8 & $\begin{array}{l}150 a \\
900\end{array}$ & 3 a 3,5 & $\begin{array}{l}0,30 a \\
0,40\end{array}$ & ano inteiro & $\begin{array}{l}1 \text { a } 2 \text { x mês; } \\
3 \text { a } 4 x \\
\text { semana }\end{array}$ & $\begin{array}{l}\text { beira do } \\
\text { capim, } \\
\text { coroa }\end{array}$ & $\begin{array}{l}1,5 \text { a } 3 \\
m\end{array}$ & 5 ou $6 \mathrm{~h}$ \\
\hline Pescadinha & $\begin{array}{l}\text { caceio } \\
\text { cerco } \\
\text { fundeio } \\
\text { arrasto }\end{array}$ & 5 a 10 & $\begin{array}{l}140 \mathrm{a} \\
700\end{array}$ & 2 a 5 & $\begin{array}{l}0,30 a \\
0,45\end{array}$ & ano inteiro & $\begin{array}{l}3 \text { a } 4 x \\
\text { semana }\end{array}$ & $\begin{array}{l}\text { coroa, } \\
\text { costão }\end{array}$ & $\begin{array}{l}1,5 \text { a } 15 \\
m\end{array}$ & $\begin{array}{l}4 \text { a } 6 \mathrm{~h} ; 12 \mathrm{~h} \mathrm{a} \\
5 \text { dias } \\
\text { (fundeio) }\end{array}$ \\
\hline Corvina & $\begin{array}{l}\text { caceio } \\
\text { fundeio }\end{array}$ & 10 a 14 & $\begin{array}{l}140 \mathrm{a} \\
500\end{array}$ & 2 a 7 & $\begin{array}{l}0,40 \mathrm{a} \\
0,70\end{array}$ & $\begin{array}{l}\text { ano inteiro; } \\
\text { mês que } \\
\text { não tem } \mathrm{R}\end{array}$ & $\begin{array}{l}4^{\circ} \text { de lua; } \\
\text { todo dia }\end{array}$ & $\begin{array}{l}\text { canal, } \\
\text { pedra }\end{array}$ & $\begin{array}{l}6 \text { a } 18 \\
m\end{array}$ & $\begin{array}{l}\text { fundeio: } 12 \mathrm{~h} \\
\text { a } 8 \text { dias; } \\
\text { caceio: } 2 \text { a } 6 \mathrm{~h}\end{array}$ \\
\hline Betara & \begin{tabular}{|l} 
caceio \\
cerco \\
fundeio
\end{tabular} & 6 a 8 & $\begin{array}{l}100 \mathrm{a} \\
700\end{array}$ & 3 a 4 & $\begin{array}{l}0,30 \mathrm{a} \\
0,40\end{array}$ & ano inteiro & $\begin{array}{l}\text { todo dia; } 3 \text { a } \\
4 \times \text { semana }\end{array}$ & $\begin{array}{l}\text { coroa, } \\
\text { cascalho }\end{array}$ & até $6 \mathrm{~m}$ & $\begin{array}{l}6 \mathrm{~h} ; \text { fundeio: } \\
12 \mathrm{~h}\end{array}$ \\
\hline \multicolumn{11}{|c|}{ Legenda: } \\
\hline \multicolumn{11}{|c|}{ E-sp: etnoespécie alvo } \\
\hline \multicolumn{6}{|c|}{ MP: modalidade de pesca } & \multicolumn{5}{|c|}{ f: freqüência de pescarias no periodo de pesca } \\
\hline \multicolumn{6}{|c|}{ \#: tamanho da malha entre nós opostos $(\mathrm{cm})$} & \multicolumn{5}{|c|}{ Lc: local de pesca } \\
\hline \multicolumn{6}{|c|}{ L: comprimento da rede (m) } & \multicolumn{4}{|c|}{ Pr: profundidade } & \\
\hline \multicolumn{6}{|c|}{$H:$ altura da rede $(\mathrm{m})$} & \multicolumn{5}{|c|}{$t:$ tempo de pesca } \\
\hline
\end{tabular}


PINHEIRO, L.; CREMER, M. Sistema pesqueiro da Baía da Babitonga, litoral...

profissionais e empregados em outros setores, ao uso de petrechos inadequados por parte de muitos, à poluição pelo turismo, à cultura de acúmulo e ao imediatismo, provocados pela "cultura urbana", que desmantela assim o sistema de subsistência (PINHEIRO, em preparação).

Essas questões são da esfera socioambiental e revelam a perda da diversidade biológica e da dignidade humana.

\section{Discussão}

Até que ponto os pescadores locais já estão aculturados ou foram assimilados pela sociedade do acúmulo de riqueza e do (não-)investimento de esforço a longo prazo? A introdução da cultura do acúmulo também poderia desequilibrar essa relação entre o trabalho e o desfrute, alterando a qualidade de vida?

Essa situação pode ser abordada com a adoção do conceito de neotradicionalidade. Sistemas neotradicionais de manejo de recursos são aqueles que apresentam elementos de sistemas tradicionais e elementos de sistemas recentes e emergentes. Assim, populações neotradicionais são aquelas que possuem conhecimentos tradicionais $\mathrm{e}$ novos, provindos do externo. É certo que todas as populações apresentam novas variedades de conhecimento adquirido, mas pode haver uma graduação na proporção do que é velho e novo (BEGOSSI, 2001).

A Baía da Babitonga vem sofrendo, de um modo geral, impactos externos no que diz respeito a mudanças de valores, pela influência de outras culturas. Verificou-se o desmantelamento da cultura de subsistência, pela divergência de opiniões e atitudes entre os pescadores, que percebem que os recursos naturais estão diminuindo ou se esgotando, além de terem clara percepção dos prejuízos que sofrem pela concorrência na pesca. O modelo de cultura de subsistência está possivelmente mais ligado aos ciclos da natureza. Supõe-se que, na cultura de subsistência, é valorizada a natureza que provê o sustento cotidiano. Acerca da etnoconservação dos recursos marinhos, ou seja, dos métodos tradicionais de conservação marinha, Polunin (1984) considerou que há um sistema de controle da exploração dos recursos marinhos por parte dos pescadores, profundos conhecedores da região que habitam, e que, dessa forma, estes percebem seus limites muito melhor do que pessoas continentais. Em contraste com tal sistema, Johannes (1978) concluiu que a apropriação e a exploração dos recursos biológicos marinhos existem como formas de ganho e lucro, mas não de maneira limitada e conservacionista.

Traços fortes de uma cultura de subsistência são percebidos em pescadores mais antigos. Entretanto, precisa ser testada a hipótese de que, ao contrário dos mais jovens, os mais velhos, portanto mais tradicionais, seriam os que têm um estreito laço com a natureza, desenvolvendo, ao contrário dos mais jovens, posturas mais conservacionistas.

A reflexão aqui apresentada evidencia que os pescadores entrevistados possuem detalhado conhecimento acerca da ecologia dos peixes e utilizam esse conhecimento para obter um forrageio ótimo. Conhecer e estudar essa sabedoria popular pode subsidiar futuras pesquisas e propostas de conservação das espécies, além de fornecer uma dimensão do estado atual dessa fauna.

É importante considerar a necessidade de forrageio pelo pescador, isto é, sua sobrevivência baseada no extrativismo, sistema cultivado e transmitido de geração para geração. As comunidades estudadas não são consumidoras especialistas, ou seja, não se alimentam exclusivamente de recursos marinhos, mas dependem direta ou indiretamente dos recursos da pesca. Os conflitos pelos quais essas comunidades vêm passando (competições pelo recurso em função do crescente número de pescadores e de influências das culturas urbanas) estão desmantelando a pesca artesanal tradicional e incentivando a "pesca predatória", assim definida pelos próprios pescadores.

\section{Agradecimentos}

Agradecimentos especiais aos pescadores da Baía da Babitonga.

Partes deste artigo foram publicadas sob o título Etnoictiologia dos trabalhadores do mar: o caso da baía da Babitonga, São Francisco do Sul. Os dados aqui apresentados foram gerados a partir do projeto "Etnoictiologia dos trabalhadores do mar: o caso da baía da Babitonga, São Francisco do Sul", amparado pelo Programa Institucional de Bolsas de Iniciação Científica (PIBIC) da Univille, sob orientação da professora Marta J. Cremer. 
PINHEIRO, L.; CREMER, M. Sistema pesqueiro da Baía da Babitonga, litoral...

TABELA 5 - DINÂMICA DE TRANSFORMAÇÃO NA EXPLORAÇÃO DOS RECURSOS PESQUEIROS, SEGUNDO OS INFORMANTES ESPECIALISTAS

\begin{tabular}{l|l}
\hline \multicolumn{1}{c|}{ "Antigamente" } & \multicolumn{1}{c}{ "Hoje em dia" } \\
\hline $\begin{array}{l}\text { Até 1950, 1960: barbantāo } \\
\text { De 1960 até 1970: fio de seda }\end{array}$ & Desde 1970: fio de nylon plástico \\
\hline $\begin{array}{l}\text { 1960, 1965: a pesca ocorria apenas na costa (praia, próximo da } \\
\text { areia) }\end{array}$ & Desde 1965: pesca no canal (quase ninguém pesca na costa) \\
\hline Pesca de engodo & Uso do gerival \\
\hline Mulheres faziam redes & Maioria dos "panos de rede" são comprados \\
\hline Cortiça de pau & \\
\hline Arrasto de gerival com força da maré & Uso de motor de popa no gerival \\
\hline
\end{tabular}

\section{REFERENCIAS}

ANDRIGUETTO FILHO, J. M. Sistemas técnicos de pesca no litoral do Paraná: caracterização e tipificação. In: RAYNAUT, C. et al. (Ed.). Desenvolvimento e Meio Ambiente - em busca da interdisciplinaridade. Curitiba: Ed. UFPR, 2002. Cap. 4 , p. 213-233.

BEGOSSI, A., HANAZAKI, N.; SILVANO, R. A. M. Ecologia humana, etnoecologia e conservação. Métodos de coleta e análise de dados em etnobiologia, etnoecologia e disciplinas correlatas. In: SEMINÁRIO DE ETNOBIOLOGIA E ETNOECOLOGIA DO SUDESTE, 1., 2002, Rio Claro. Anais... Rio Claro: Unesp/CNPq. p. 93-128.

CASTEllo, J. P.; HAIMOVICI, M. Simpósio da FURG sobre pesquisa pesqueira: comentários e recomendações. Atlântica, v. 1, n. 13, p. 5-9, 1991.

CHARLES, A. T. Bio-socio-economic dynamics and multidisciplinary models in small-scale fisheries research. In: DURAND, J. R.; LEMOALLE, J.; WEBER, J. (Ed.). La Recherche Face à la Pêche Artisanale. Symposium International Orstom-Ifremer, Montpellier. Paris: Orstom, 1991. t. 2, p. 603-608.

CORLAY, J. P. Le concept d'espace halieutique: réflexions de géographe sur les pêches maritimes à partir du cas danois. In: LALOË, F.; REY, H.; DURAND, J. L. (Ed.). Questions surla dynamique de l'exploitation halieutique. Paris: Orstom, 1995. (Collection Colloques et Séminaires), p. 125-140.

CORMIER-SALEM, M. C. Gestion et évolution des espaces aquatiques: la Casamance. Paris: Orstom, 1992. (Collection Études et Thèses), 583 p.

DURAND, J. R.; LEMOALLE, J.; WEBER, J. (Ed.). La Recherche Face à la Pêche Artisanale. Symposium International Orstom-Ifremer, Montpellier. Paris: Orstom, 1991. $1070 \mathrm{p}$.
FATMA. A Baía da Babitonga: Relatório técnico. Joinville: Fatma, 1984.

JOHANNES, R. E. Traditional marine conservation methods in Oceania and their demise. Annual Review of Ecology' and Systematics, v. 9, p. 349-364, 1978.

MARQUES, J. G. W. Pescando pescadores: ciência e etnociência em uma perspectiva ecológica. 2. ed. São Paulo: Núcleo de Apoio à Pesquisa Sobre Populações Humanas e Áreas Úmidas Brasileiras - USP, 2001.

PINHEIRO, L. Etnoictiologia dos trabalhadores do mar: o caso da baía da Babitonga, São Francisco do Sul. Joinville, 2002. 72 f. Monografia (Bacharelado em Ciências Biológicas) - Universidade da Região de Joinville.

PINHEIRO, L. Gênero, cultura e meio ambiente: aspectos da divisão de trabalho em comunidades pesqueiras tradicionais da baía da Babitonga. Artigo em elaboração.

POLUNIN, N. V. C. Do traditional marine "reserves" conserve? A view of Indonesian and New Guinean evidence. Senri Ethnoecological Studies, v. 17, p. 267-283, 1984.

QUENSIÈRE, J. (Ed.). La pêche dans le Delta Central du Niger. Approche pluridisciplinaire d'un système de production halieutique. Paris: Orstom, 1994. 495 p.

QUENSIÈRE, J. Quelles conditions pour une gestion durable des pêcheries artisanales? Natures - Sciences - Societés, v. 1, n. 4, p. 75-76, 1996.

RICKLEFS, R. E. A economia da natureza. 3. ed. Rio de Janeiro: Guanabara Koogan, 1996.

RIOS, G. S. L. A pesca artesanal como parte do setor de subsistência: sua abordagem sociológica. Ciência e Cultura, v. 4 , n. 28 , p. $397-406$, abr. 1976. 
PINHEIRO, L.; CREMER, M. Sistema pesqueiro da Baía da Babitonga, litoral...

RODRIGUES, A. M. T. et al. Proteçâo e controle de ecossistemas costeiros: manguezal da Baía da Babitonga. Brasília: Ibama, 1998.

SILVA, F. J. da. Unidades de conservação e desenvolvimento regional: um estudo sobre a região da Baía da Babitonga - SC.
Florianópolis, 1995. Dissertação (Mestrado) - Universidade Federal de Santa Catarina.

TOLEDO, V. M. What is Ethnoecology? Origins, scope and implications of a rising discipline. Etnoecológica, v. 1, n. 1, p. 5-20, 1992. 